\title{
RECUPERATION, TRANSFORMATION AND THE TRANSCENDENCE OF MAJOR OVER MINOR IN THE FINALE OF HAYDN'S STRING QUARTET OP. 76 NO. 1 - CORRIGENDUM
}

\author{
F L O Y D G A V E
}

Eighteenth-Century Music 5/1, 27-50 (C) 2008 Cambridge University Press doi:10.1017/S147857060800119X Printed in the United Kingdom

FLOYD GRAVE writes:

In my 'Recuperation, Transformation and the Transcendence of Major over Minor in the Finale of Haydn's String Quartet Op. 76 No. 1', Eighteenth-Century Music 5/1, Figure 1 on page 42 was reproduced incorrectly. The corrected figure and the accompanying caption are given below.

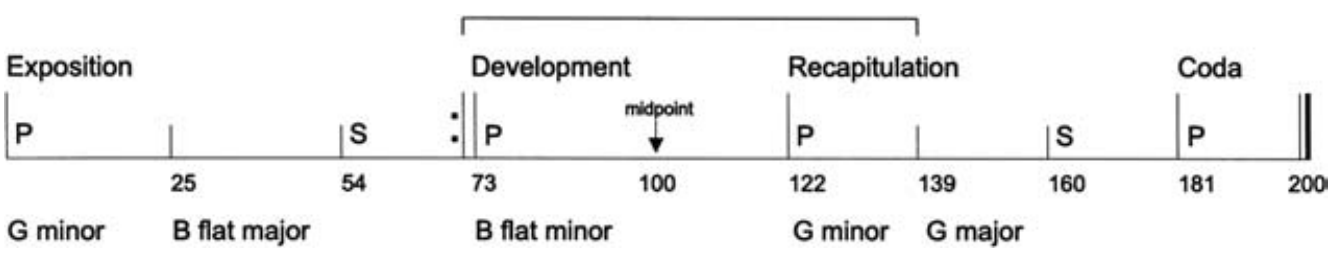

Figure 1 Haydn, String Quartet in G major, Op. 76 No. 1/iv. Approximate structural proportions and selected salient features are displayed in accordance with the 'timeline' method proposed in Jan LaRue, Guidelines for Style Analysis, second edition (Warren, MI: Harmonie Park, 1992). The central, minor-dominated span delineated by brackets (bars 73-138) encompasses the development section and the beginning of the recapitulation. This portion of the design is outlined in detail in Table 2b, below

\section{Reference}

1. Grave, F. Recuperation, transformation and the transcendence of major over minor in the finale of Haydn's string quartet op. 76 no. 1. Eighteenth-Century Music Published by Cambridge University Press, 04 April 2008. doi:10.1017/S147857060800119X 